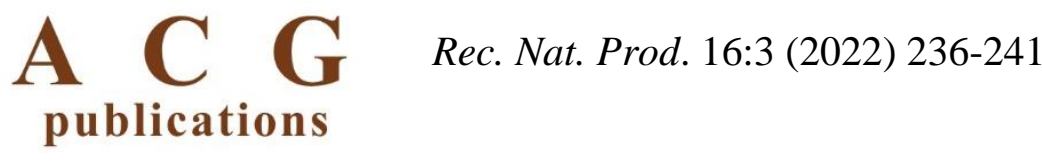

\title{
Anti-Inflammatory Components from the Fruits of
}

\section{Amomum aromaticum}

\section{Nguyen Hai Dang $\oplus^{1}$, Le Nguyen Thanh $\oplus^{2 *}$, Do Hoang Giang $\oplus^{3}$ and Nguyen Tien Dat ${ }^{3 *}$}

\author{
${ }^{1}$ University of Science and Technology of Hanoi, Vietnam Academy of Science and Technology \\ (VAST), 18 Hoang Quoc Viet, Cau Giay, Hanoi, Vietnam \\ ${ }^{2}$ Institute of Marine Biochemistry, VAST, 18 Hoang Quoc Viet, Cau Giay, Hanoi, Vietnam \\ ${ }^{3}$ Center for Research and Technology Transfer, VAST, 18 Hoang Quoc Viet, Cau Giay, Hanoi,
}

Vietnam

(Received May 04, 2021; Revised June 25, 2021; Accepted July 08, 2021)

\begin{abstract}
In the course of searching for bioactive components from a Vietnamese spice, the fruits of Amomum aromaticum, a new bicyclic nonane (1) and seven known compounds including 4 monoterpenes $(\mathbf{2}, \mathbf{3}, \mathbf{5}, \mathbf{6})$, one fatty acid (4), and two steroids (7-8) were isolated. Their structures were determined on the basis of spectroscopic analysis. This is the first report of compounds tsaokoin (2), $1 \beta, 2 \alpha$-dihydroxy-p-menth-5-ene (3), oleic acid (4), $\beta$ sitosterol (7), and daucosterol (8) in A. aromaticum. To evaluate the anti-inflammatory activities of the isolates, we measured their inhibitory activity against lipopolysaccharide-induced nitric oxide production in a RAW264.7 murine macrophage model. The new compound rel-(1S,5R,6S)-5-methoxybicyclo[4.3.0]non-2-ene-2carbaldehyde (1) and tsaokoin (2) showed substantial anti-inflammatory effects, with $\mathrm{IC}_{50}$ values of 17.78 and 6.31 $\mu \mathrm{M}$, respectively. Thus, A. aromaticum fruits could be a rich source for the discovery of anti-inflammatory agents.
\end{abstract}

Keywords: Amomum aromaticum; bicyclic nonane; tsaokoin; anti-inflammation. (C) 2021 ACG Publications. All rights reserved.

\section{Introduction}

Amomum aromaticum Roxb., which belongs to the Zingiberaceae family, is a well-known aromatic plant distributed widely in Vietnam. It is a traditional spice used in various dishes and is notably an indispensable ingredient of the famous Vietnamese beef soup Pho. In addition, traditional medicine has used these fruits to treat abdominal pain, stomach disorders, nausea, diarrhea, malaria, sore throat, cough, and toothache $[1,2]$. The essential oil of A. aromaticum contains mostly eucalyptol, citral, 2decenal, and neral, which are anti-leishmanial agents [3]. Recently, we reported that the essential oil of A. aromaticum fruits inhibited nitric oxide (NO) production and reduced the expression of two key

\footnotetext{
* Corresponding authors: E-Mail: lethanh@imbc.vast.vn; ngtiend@imbc.vast.vn Phone: 084-243-791-7053 Fax: 084-243-791-7054 
enzymes involved in the inflammation process, iNOS and COX-2, in lipopolysaccharide (LPS)stimulated RAW264.7 cells [4]. Besides these reports on the essential oil, other chemical constituents of $A$. aromaticum have not been investigated so far.

The present paper describes the isolation and identification of a new bicyclic nonane (1) and seven known compounds (2-8) from the EtOAc fraction of A. aromaticum fruits. We also evaluated the antiinflammatory effect of the isolated components by assessing their NO production inhibitory activity in RAW 264.7 macrophages.

\section{Materials and Methods}

\subsection{Plant Materials}

Amomum aromaticum fruits were collected in Dong Van commune, Ha Giang province, Vietnam, in November 2019 and taxonomically determined by Dr. Nguyen The Cuong, Institute of Ecology and Biological Resources, VAST. Voucher specimen was deposited at the Institute of Marine Biochemistry, VAST.

\subsection{General Experimental Procedures}

The ${ }^{1} \mathrm{H}$ NMR (500 MHz) and ${ }^{13} \mathrm{C}$ NMR experiments were recorded on a Bruker AM500 FT-NMR spectrometer with tetramethylsilane (TMS) was used as an internal standard. High-resolution mass spectra (HR-ESI-MS) were obtained with a Thermo LTQ Orbitrap XL mass spectrometer. Column chromatography (CC) was performed on silica gel 60 (70-230 mesh, Merck) or Sephadex LH-20® (Sigma-Aldrich). Thin-layer chromatography (TLC) was performed on DC-Alufolien silica gel $60 \mathrm{~F}_{254}$ plates (Merck, Germany). Spots were visualized under UV illumination $254 \mathrm{~nm}$ and spraying with $\mathrm{H}_{2} \mathrm{SO}_{4} 10 \%$ reagents, followed by heating. HPLC was carried out on an Agilent 1260 series HPLCDAD system.

\subsection{Extraction and Isolation}

The fruits of A. aromaticum ( $3.5 \mathrm{~kg}$ ) were dried and grinded into powder. The fruit material was macerated three times with $\mathrm{MeOH}$ at room temperature $(10 \mathrm{~L}$ for 1 day each time). The extracts were combined and removed $\mathrm{MeOH}$ under vacuum to obtain a residue $(450 \mathrm{~g})$. The $\mathrm{MeOH}$ residue was suspended in water and then successively partitioned with $n$-hexane and EtOAc. Evaporation of the organic solvents under vacuum gave $n$-hexane $(53 \mathrm{~g})$ and EtOAc residues (140 g), respectively.

The EtOAc residues $(140 \mathrm{~g})$ was subjected on a silica gel column and eluted with a gradient solvent system of $n$-hexane-EtOAc (100:1 - 0:1, v/v) to afford 10 fractions E1-E10, respectively. Fraction E6 (2.8 g) was chromatographed on silica gel CC, eluted with $n$-hexane-acetone $(4: 1, \mathrm{v} / \mathrm{v})$ to give 4 fractions E6A-E6D. Fraction E6D was separated by silica gel CC and eluted with $n$-hexane$\mathrm{CH}_{2} \mathrm{Cl}_{2}(20: 1, \mathrm{v} / \mathrm{v})$ to yield compound $\mathbf{1}(8 \mathrm{mg})$. Fraction E6A was purified by silica gel CC and eluted with $n$-hexane-acetone $(4: 1, \mathrm{v} / \mathrm{v})$ to afford compound $4(10 \mathrm{mg})$. Compound $7(12 \mathrm{mg})$ was crystallized and obtained from the fraction E6C. Fraction E7 (16 g) was separated on silica gel CC eluting with a gradient solvent system of $n$-hexane-acetone (100:1 - 9:1, v/v) to give 3 fractions E7A- E7C. Fraction E7A was subjected to a silica gel CC and eluted with $n$-hexane- $\mathrm{CH}_{2} \mathrm{Cl}_{2}(20: 1, \mathrm{v} / \mathrm{v})$ to yield compound 2 (300 mg). Fraction E7C was separated by column chromatography on silica gel and eluted with $n$ hexane- $\mathrm{CH}_{2} \mathrm{Cl}_{2}(10: 1, \mathrm{v} / \mathrm{v})$ to give compound $\mathbf{3}(24 \mathrm{mg})$. Fraction E3 $(13 \mathrm{~g})$ was further chromatographed on a silica gel column eluting with $n$-hexane- $\mathrm{CH}_{2} \mathrm{Cl}_{2}(100: 1-20: 1$, v/v) to give 4 fractions E3A-E3D. Fraction E3A was purified by a silica gel CC, eluted with $n$-hexane- $\mathrm{CH}_{2} \mathrm{Cl}_{2}(50: 1, \mathrm{v} / \mathrm{v})$ to give compound $5(6 \mathrm{mg})$. Fraction E3D was subjected to a column chromatography on silica gel eluted with $n$-hexane$\mathrm{CH}_{2} \mathrm{Cl}_{2}(50: 1, \mathrm{v} / \mathrm{v})$ to yield compound $6(7 \mathrm{mg})$. Fraction E9 $(15 \mathrm{~g})$ was repeatedly purified on Sephadex LH-20 CC eluting with $\mathrm{MeOH}-\mathrm{CH}_{2} \mathrm{Cl}_{2}(9: 1, \mathrm{v} / \mathrm{v})$ to afford compound $8(20 \mathrm{mg})$. 
Rel-(1S,5R,6S)-5-methoxybicyclo[4.3.0]non-2-ene-2-carbaldehyde (1): Yellow oil, $[\alpha]_{\mathrm{D}}{ }^{25} 0$ (c 2.2, $\left.\mathrm{CHCl}_{3}\right) ;{ }^{1} \mathrm{H}-\mathrm{NMR}\left(500 \mathrm{MHz}, \mathrm{CDCl}_{3}\right) \delta_{\mathrm{H}}(\mathrm{ppm}): 9.41(1 \mathrm{H}, \mathrm{s}, \mathrm{H}-10), 6.57(1 \mathrm{H}, \mathrm{dd}, J=4.0 \mathrm{~Hz}, 2.0 \mathrm{~Hz}$, H-3), $3.68(1 \mathrm{H}$, br d, $J=4.0 \mathrm{~Hz}, \mathrm{H}-5), 3.37$ (3H, s, 5-OMe), 2.72 (1H, ddd, $J=20.5,4.0,2.0 \mathrm{~Hz}, \mathrm{H}-4 \alpha$ ), $2.50(1 \mathrm{H}, \mathrm{m}, \mathrm{H}-9 \alpha), 2.43(1 \mathrm{H}$, ddd, $J=20.5,4.0,2.0 \mathrm{~Hz}, \mathrm{H}-4 \beta), 2.35(1 \mathrm{H}, \mathrm{m}, \mathrm{H}-1), 1.73(2 \mathrm{H}, \mathrm{m}, \mathrm{H}-8)$, $1.58(2 \mathrm{H}, \mathrm{m}, \mathrm{H}-7), 1.45(1 \mathrm{H}, \mathrm{m}, \mathrm{H}-6), 1.17$ (ddd, $J=12.5,10.0,9.5 \mathrm{~Hz}, \mathrm{H}-9 \beta) .{ }^{13} \mathrm{C}-\mathrm{NMR}(125 \mathrm{MHz}$, $\left.\mathrm{CDCl}_{3}\right) \delta_{\mathrm{C}}(\mathrm{ppm}): 193.7(\mathrm{C}-10), 148.5(\mathrm{C}-3), 145.2(\mathrm{C}-2), 74.4(\mathrm{C}-5), 57.4(5-\mathrm{OMe}), 47.8$ (C-6), 35.4 (C-1), 32.6 (C-4), 27.6 (C-9), 24.2 (C-7), 22.3 (C-8). HR-ESI-MS: m/z 179.1065 [M - H] ${ }^{-}$(calcd. for $\mathrm{C}_{11} \mathrm{H}_{15} \mathrm{O}_{2}$ 179.1072).<smiles>CO[C@H]1CC=C(C=O)[C@H]2CCC[C@H]12</smiles>

1<smiles>O=CC1=CC[C@@H](O)[C@H]2CCC[C@H]12</smiles>

2<smiles>CC(C)[C@@H]1C=C[C@@](C)(O)[C@H](O)C1</smiles>

3<smiles>C=CC(C)(O)CCC=C(C)CCC=C(C)C</smiles>

5<smiles>CC(C)=CCCC(C)=CC=O</smiles>

6

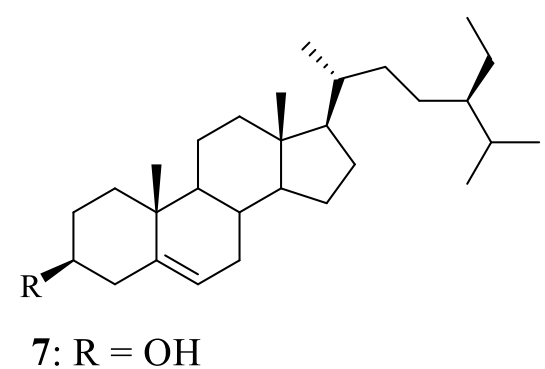

8: $\mathrm{R}=\mathrm{O}-\mathrm{b}-\mathrm{D}-$ glucopyranoside

Figure 1. The structure of compounds isolated from Amomum aromaticum

\subsection{NO Production Inhibitory Assay}

Murine macrophages RAW264.7 were cultured in a $10 \mathrm{~cm}$ petri dish at a density of $1 \times 10^{4}$ cells/well with DMEM supplemented with $10 \%$ fetal bovine serum (Gibco, Invitrogen, USA), $1 \%$ penicillin \& streptomycin (Gibco, Invitrogen, USA). We kept the cells in a humidified incubator at $37^{\circ} \mathrm{C}$ with $5 \% \mathrm{CO}_{2}$. We changed the medium every 1-2 days until the cells were ready for the NO production inhibition assay. We seeded the cells in 96-well plates at $2 \times 10^{4}$ cells per well and incubated them in the humidified incubator at $37^{\circ} \mathrm{C}, 5 \% \mathrm{CO}_{2}$ for $24 \mathrm{~h}$. We then pretreated the cells with compounds at different concentrations. After $30 \mathrm{~min}$, we stimulated them with $1 \mu \mathrm{g} / \mathrm{mL}$ LPS (Escherichia coli 0111: B4; Sigma Aldrich, USA) and incubated them for $24 \mathrm{~h}$. We transferred $100 \mu \mathrm{L}$ of cell supernatant from each well to another 96 -well plate and added $100 \mu \mathrm{L}$ of Griess reagent ( $50 \mu \mathrm{L}$ Griess A and $50 \mu \mathrm{L}$ Griess B). We measured the absorbance of the samples at $540 \mathrm{~nm}$ with an iMark microplate spectrophotometer (BioRad, USA). We used fresh culture medium as a blank sample in all experiments. We determined the nitrite quantity from a $\mathrm{NaNO}_{2}$ standard curve [4]. We performed an MTT assay on the remaining cells from the original 96-well plate to assess viability. We determined the $\mathrm{IC}_{50}$ using the Curve expert program. Cardamonin was use as the positive control [5].

\section{Results and Discussion}

\subsection{Structure Elucidation}

Compound 1 was isolated as a pale brown oil with the molecular formula $\mathrm{C}_{11} \mathrm{H}_{16} \mathrm{O}_{2}$, which was established from the HR-ESI-MS spectrum with the ion peak $m / z$ 179.1065 $[\mathrm{M}-\mathrm{H}]^{-}$. The ${ }^{1} \mathrm{H}$ NMR spectrum of 1 revealed an aldehyde proton at $\delta_{\mathrm{H}} 9.40(1 \mathrm{H}, \mathrm{s}, \mathrm{H}-10)$, an olefinic proton at $\delta_{\mathrm{H}} 6.57(1 \mathrm{H}$, $\mathrm{dd}, J=2 \mathrm{~Hz}, \mathrm{H}-3)$, an oximethine signal at $\delta_{\mathrm{H}} 3.68(1 \mathrm{H}, \mathrm{d}, J=4.0 \mathrm{~Hz}, \mathrm{H}-5)$ and a methoxy group at $\delta_{\mathrm{H}}$ $3.37(3 \mathrm{H}, \mathrm{s}, \mathrm{H}-11)$. The ${ }^{13} \mathrm{C}$ NMR and HSQC spectra displayed 11 signals, namely, a carbaldehyde at 
193.7 ppm, five methines, four methylenes, and a methoxy group. Figure 2 shows the ${ }^{1} \mathrm{H}-{ }^{1} \mathrm{H}$ COSY (cross-peaks: H-4/H-3 and H-5, H-1/H-6 and H-9, H-8/H-9 and H-7) and key HMBC correlations from H-1 to C-10 or C-3, H-10 to C-2 and C-3, H-9 to C-2 and C-7, and methoxy proton to C-5. These data suggested that 1 was a methyl ether derivative of 5-hydroxybicyclo[4.3.0]non-2-ene-2-carbaldehyde compounds such as tsaokoin (2), isotsaokoin, or (1RS,5SR,6RS)-5-hydroxybicyclo[4.3.0]non-2-ene-2carbaldehyde previously found in Amomum species [6,7]. We determined the relative configuration of 1 thanks to ${ }^{1} \mathrm{H}-{ }^{1} \mathrm{H}$ coupling constants and a NOESY experiment. The absence of ${ }^{1} \mathrm{H}-{ }^{1} \mathrm{H}$ correlation between $\mathrm{H}-1$ and $\mathrm{H}-6$ on the NOESY spectrum indicated that two rings were trans-fused. The antipositions of H-1 and H-6 were further confirmed by the NOE correlations of H-6 to H-5, H- $4 \beta$, and H$9 \beta$ and of $\mathrm{H}-1$ to $\mathrm{H}-9 \alpha$ but not $\mathrm{H}-9 \beta$. Moreover, the absence of ${ }^{1} \mathrm{H}-{ }^{1} \mathrm{H}$ correlation between $\mathrm{H}-10$ and $\mathrm{H}-$ 1 revealed the pseudoaxial orientation of $\mathrm{H}-1$. The ${ }^{1} \mathrm{H}-{ }^{1} \mathrm{H}$ correlations between the methoxy proton and $\mathrm{H}-4$, between $\mathrm{H}-5$ and H-6, together with the small coupling constant of $\mathrm{H}-5(\mathrm{~J}=4.0 \mathrm{~Hz})$, revealed the pseudoequatorial orientation of H-5 [7]. Compound 1 had an optical rotation of zero, indicating a racemic mixture, similar to most carbaldehyde monoterpenes isolated from Amomum species [6-9]. Thus, we identified compound $\mathbf{1}$ as rel-(1S,5R,6S)-5-methoxybicyclo[4.3.0]non-2-ene-2-carbaldehyde.

Since compound $\mathbf{1}$ was a methyl ether product, it is possibly an artifact formed during the $\mathrm{MeOH}$ extraction. However, we detected compound 1 in the HPLC analysis of the EtOH extract of $A$. aromaticum (retention time: $24.7 \mathrm{~min}$; see Supplemental Figure S12). This confirmed that 1 was a natural constituent of the A. aromaticum fruits.
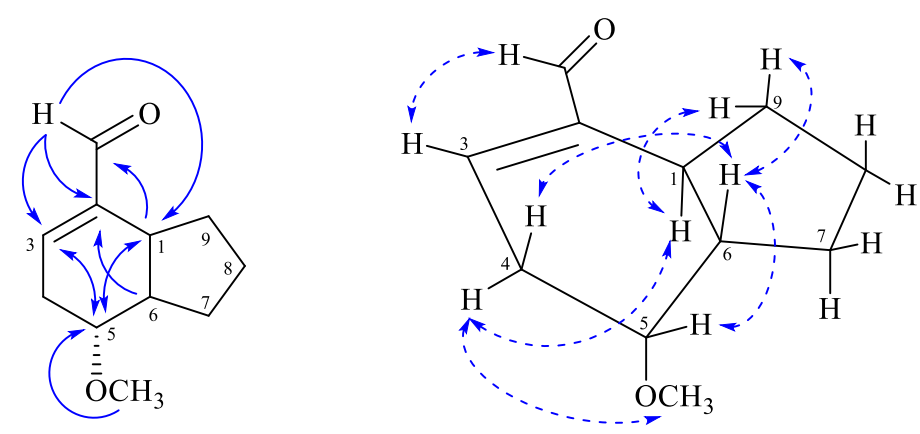

Figure 2. Key HMBC and NOESY correlations of compound 1

We identified the remaining compounds (which included four monoterpenes: tsaokoin (2) [6], 1 $\beta, 2 \alpha$-dihydroxy-p-menth-5-ene (3) [10], $E$-nerolidol (5) [11], and citral (6) [12]; one fatty acid: oleic acid (4) [13]; and two steroids: $\beta$-sitosterol (7) [14] and daucosterol (8) [15]) by comparing their NMR data to previous publications (Figure 1). Compounds 2, 3, 4, 7, and 8 were first identified in $A$. aromaticum.

Monoterpenes 2, 3, 5, and $\mathbf{6}$ are found in essential oils from several cardamom species. These substances greatly contribute to the biological activity of cardamom plants. In our previous study, citral (6) (a mixture of neral and geranial) and $E$-nerolidol (5) respectively represented $15.96 \%$ and $1.69 \%$ of the total essential oil content [4]. $\beta$-Sitosterol (7) and daucosterol (8) are common phytosterols playing essential roles in plant physiology. These steroids have been consumed as food or pharmaceutical products. They showed various pharmaceutical properties such as immunomodulating, anti-cancer, and anti-tuberculosis activity [16].

\subsection{NO Production Inhibitory Activity}

The inhibitory effects of the isolated compounds on LPS-induced NO production in RAW264.7 cells were evaluated. Only bicyclic nonane compounds $\mathbf{1}$ and $\mathbf{2}$ significantly inhibited NO production with $\mathrm{IC}_{50}$ values of $17.78 \pm 2.34$ and $6.31 \pm 1.12 \mu \mathrm{M}$, respectively. However, these values were lower than that of the positive control cardamonin $(2.24 \pm 1.27 \mu \mathrm{M})$. The MTT test revealed no cytotoxicity for these two compounds on RAW264.7 cells (data not shown). Compounds $\mathbf{3}-\mathbf{8}$ were either inactive or toxic at the screening concentration of $50 \mu \mathrm{M}$ (Table 1). 
Anti-inflammatory components from Amomum aromaticum

The bicyclic nonanes tsaokoin and isotsaokoin inhibit NO production in murine BV2 microglial cells [17]. Consistently, our assay showed that tsaokoin (2) had a similar effect on RAW264.7 macrophages. Compound $\mathbf{1}$ exhibited a lower activity, suggesting that the addition of the methyl ether group or the change in configuration at $\mathrm{C}-1$ might reduce the inhibition of NO production.

Table 1. NO production inhibitory activity of compounds 1-8

\begin{tabular}{cc} 
Compound & $\mathbf{I C}_{\mathbf{5 0}}(\mu \mathbf{M})^{\mathrm{a}}$ \\
\hline $\mathbf{1}$ & $17.78 \pm 2.34$ \\
$\mathbf{2}$ & $6.31 \pm 1.12$ \\
$\mathbf{3}$ & $\mathrm{ND}$ \\
$\mathbf{4}$ & $\mathrm{ND}$ \\
$\mathbf{5}$ & $>50$ \\
$\mathbf{6}$ & $>50$ \\
$\mathbf{7}$ & $>50$ \\
$\mathbf{8}$ & $>50$ \\
Cardamonin* $^{*}$ & $2.24 \pm 1.27$ \\
\hline
\end{tabular}

*Positive control, ND: not detected. ${ }^{a}$ Data obtained from a triplicate experiment.

In summary, we isolated eight compounds from the EtOAc extract of A. aromaticum fruits for the first time. We identified their structures as $r e l-(1 S, 5 R, 6 S)-5$-methoxybicyclo[4.3.0]non-2-ene-2carbaldehyde (1, a new compound), tsaokoin (2), 1 $\beta, 2 \alpha$-dihydroxy-p-menth-5-ene (3), oleic acid (4), $E$ nerolidol (5), citral (6), $\beta$-sitosterol (7), and daucosterol (8). Compounds 1 and 2 significantly inhibited LPS-induced NO production in RAW264.7 cells. The bicyclic nonanes seem to be important components contributing to the anti-inflammatory properties of A. aromaticum fruits. Besides reports on the essential oil components, research on the chemical constituents of this plant has been sparse. The discovery of anti-inflammatory compounds in A. aromaticum fruits could add value to the use of this spice in food and promote the search for its bioactive phytochemicals.

\section{Acknowledgments}

This research is funded by Vietnam National Foundation for Science and Technology Development (NAFOSTED) under grant number 104.01-2017.307.

\section{Supporting Information}

Supporting information accompanies this paper on http://www.acgpubs.org/journal/records-ofnatural-products

\section{ORCID}

Nguyen Hai Dang: 0000-0002-4470-8321

Le Nguyen Thanh: 0000-0002-8375-4187

Do Hoang Giang: $0000-0001-9227-6992$

Nguyen Tien Dat: $\underline{0000-0003-3645-5157}$

\section{References}

[1] V. V. Chi (2012). Dictionary of Vietnamese medicinal plants, Medical Publishing House, Hanoi, Vietnam.

[2] T. K. Lim (2012). Edible medicinal and non-medicinal plants, Springer, Dordrecht, Netherlands. 
[3] T. B. Le, C. Beaufay, D.T. Nghiem, M.-P. Mingeot-Leclercq and J. Quetin-Leclercq (2017). In vitro antileishmanial activity of essential oils extracted from Vietnamese plants, Molecules 22, 1071.

[4] N. H. Dang, L. T. V. Anh and N. T. Dat (2020). Anti-inflammatory effects of essential oils of Amomum aromaticum fruits in lipopolysaccharide-stimulated RAW264.7 cells, J. Food Qual. ID 8831187.

[5] S. Hatziieremia, A. I. Gray, V. A. Ferro, A. Paul and R. Plevin (2006). The effects of cardamonin on lipopolysaccharide-induced inflammatory protein production and MAP kinase and NFkappaB signalling pathways in monocytes/macrophages, Br. J. Pharmacol. 149, 188-198.

[6] S.-S. Moon, J.-Y. Lee and S.-C. Cho (2004). Isotsaokoin, an antifungal agent from Amomum tsao-ko, J. Nat. Prod. 67, 889-891.

[7] X. Yang, P. Kuenzi, I. Plitzko, O. Potterat and M. Hamburger (2009). Bicyclononane aldehydes and antiproliferative constituents from Amomum tsao-ko, Planta Med. 75, 543-546.

[8] B.-C. Hong, H.-C. Tseng and S.-H. Chen (2007). Synthesis of aromatic aldehydes by organocatalytic $[4+2]$ and [3+3] cycloaddition of $\alpha, \beta$-unsaturated aldehydes, Tetrahedron 63, 2840-2850.

[9] C. Starkenmann, F. Mayenzet, R. Brauchli, L. Wunsche and C. Vial (2007). Structure elucidation of a pungent compound in black Cardamom: Amomum tsao-ko Crevost et Lemarie (Zingiberaceae), J. Agric. Food Chem. 55, 10902-10907.

[10] X. Liu, Q.-X. Wu and Y.-P. Shi (2005). Terpenoids from the flower of Cacalia tangutica, J. Chin. Chem. Soc. 52, 369-374.

[11] S. M. F. Machado, V. A. F. A. Ribeiro, J. S. L. T. Militão, S. M. de Morais, M. I. L. Machado (1998). Seasonal variation of $(E)$-Nerolidol in Siparuna guianensis Aublet and ${ }^{13} \mathrm{C}-\mathrm{NMR}$ spectral assignments of (E)- and (Z)-nerolidol, J. Essent. Oil Res. 10, 708-710.

[12] P. B. Venuto and A. R. Day (1964). The preparation of allylic alcohols from citral a and citral b. A study of their dehydration reactions, J. Org. Chem. 29, 2735-2739.

[13] G. Knothe and J. A. Kenar (2004). Determination of the fatty acid profile by 1H-NMR spectroscopy, Eur. J. Lipid Sci. Technol. 106, 88-96.

[14] A. Sen, P. Dhavan, K. K. Shukla, S. Singh and G. Tejovathi (2012). Analysis of IR, NMR and antimicrobial activity of $\beta$-sitosterol isolated from Momordica charantia, Science Secure J. Biotech. 1, $9-13$.

[15] M. Soumia, H. Hamada, L. Catherine, L. Christophe and B. Mohammed (2012). Chemical constituents of Centaurea omphalotricha Coss. \& Durieu ex Batt. \& Trab, Rec. Nat. Prod. 6, 292-295.

[16] D. Kritchevsky, C. S Chen (2005). Phytosterols - health benefits and potential concerns: a review, Nutr. Res. 25, 413-428.

[17] K. Y. Lee, S. H. Kim, S. H. Sung and Y. C. Kim (2008). Inhibitory constituents of lipopolysaccharideinduced nitric oxide production in BV2 microglia isolated from Amomum tsao-ko, Planta Med. 74, 867869.

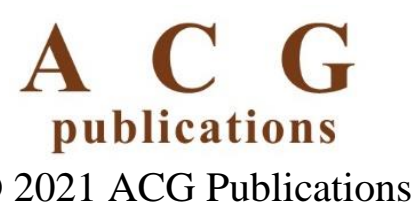

